\title{
Manufacturing Heparin with Equivalent Chemical Composition from Different Animal Sources
}

\author{
David Keire ${ }^{1}$ \\ ${ }^{1}$ Division of Pharmaceutical Analysis, Office of Testing and Research, \\ Office of Pharmaceutical Quality, Center for Drug Evaluation and \\ Research, Food and Drug Administration, St. Louis, Missouri, \\ United States
}

Thromb Haemost 2019;119:688.

Up to the 1990s, the available bovine lung and porcine intestinal sourced heparins were used interchangeably as essential life-saving anticoagulants for many different surgical interventions. In the United States, the bovine product gradually fell out of favour because the porcine-sourced heparin was more potent and, in the 1990s, concerns regarding bovine spongiform encephalopathy (BSE) agents and the risk of variant Creutzfeldt-Jakob's disease for humans. These factors caused a withdrawal of bovine sources of heparin from many markets worldwide.

Since that time, increased testing and knowledge about controls to prevent transmission of BSE agents has led to a dramatic decrease in reported BSE cases (e.g., two reported cases worldwide in $2016^{1}$ ). In addition, the global supply of heparin is a critical World Health Organization-designated essential drug and the use of pigs as the primary source has risks associated with pig disease and potential instability due to other factors. Therefore, the U.S. Food and Drug Administration hosted Science Board meetings in 2014 and $2016^{2}$ to discuss the potential re-introduction of bovine heparin to the U.S. market and in $2018^{3}$ reiterated interest in seeing bovine heparin products return to use.

Notably, in some countries like Brazil where cattle are prevalent, bovine heparin continued to be used clinically after the BSE crisis in the 1990s. Subsequently, even in Brazil the use of bovine heparin was discontinued with the implementation of new monograph requirements in 2008 for greater than $180 \mathrm{IU} / \mathrm{mg}$ for unfractionated heparin. The new monograph requirements essentially designated the use of porcine-sourced heparin, because bovine intestinal heparin has $c a .1 / 2$ the potency $\mathrm{w} / \mathrm{w}$ compared with porcine heparin. In 2017, the differences in chemical
Address for correspondence David Keire, PhD, Division of Pharmaceutical Analysis, Food and Drug Administration, $645 \mathrm{~S}$. Newstead Avenue, St. Louis, MO, 63101, United States (e-mail: David.Keire@fda.hhs.gov).

composition and potency led the Brazilian Pharmacopeia to establish separate drug monographs for porcine and bovine heparin.

In the current article by Tovar et $\mathrm{al}^{4}{ }^{4}$ a straightforward application of bovine heparin fractionation with anion exchange chromatography to produce a heparin with similar chemical composition, potency and safety profile to porcine heparin is demonstrated. If such a porcine-like heparin product could be made commercially from a bovine source and obtain approval from regulators, a single heparin drug from different animal sources with different geographical distribution with consistent quality could improve supply chain stability for this important drug.

Conflict of Interest

None declared.

\section{References}

1 Number of reported cases of bovine spongiform encephalopathy (BSE) in farmed cattle worldwide (excluding the United Kingdom). Available at: http://www.oie.int/?id=505. Accessed March 15, 2019

2 Background materials for the November 15, 2016 meeting of the science board to the FDA. Available at: https://www.fda.gov/AdvisoryCommittees/CommitteesMeetingMaterials/ScienceBoardtotheFoodandDrugAdministration/ucm527761.htm. Accessed March 15, 2019

3 FDA encourages reintroduction of bovine-sourced heparin. Available at: https://www.fda.gov/Drugs/DevelopmentApprovalProcess/Manufacturing/ucm600976.htm. Accessed March 15, 2019

4 Tovar AMF, Vairo BC, Oliveira SMCG, et al. Converting the distinct heparins sourced from bovine or porcine mucosa into a single anticoagulant drug. Thromb Haemost 2019;119(04):618-632 received

May 12, 2019

accepted after revision

May 12, 2019 (c) 2019 Georg Thieme Verlag KG Stuttgart · New York
DOI https://doi.org/

$10.1055 / \mathrm{s}-0039-1685164$. ISSN 0340-6245. 